\title{
Household recycling of compact fluorescent lights: a survey of influential factors
}

\author{
T. P. Wagner \\ Department of Environmental Science, \\ University of Southern Maine, USA
}

\begin{abstract}
Increased energy costs, government subsidies, and a successful marketing campaign has significantly increased the number of compact fluorescent lights (CFLs) installed by households in the US state of Maine. Although CFLs provide many benefits, they contain small amounts of mercury which, given the large number of CFLs in use, can become an environmental contaminant of concern unless recycled in an environmentally sound manner. Despite a ban on disposing of CFLs, the availability of free CFL collection, and a statewide education campaign, the household CFL recycling participation rate is low. A study was undertaken to identify which factors are responsible for low recycling participation by surveying 520 Maine residents who use CFLs. Based on the survey, only $23.5 \%$ of households have recycled CFLs. The survey responses indicate a lack of awareness as a primary factor in low recycling participation as nearly $70 \%$ did not know CFLs are required to be recycled or believed recycling is not required. Regarding locations for CFL drop-off, $64.2 \%$ said they did not know where CFLs could be brought for recycling and $72.9 \%$ said they were unaware that CFL collection and recycling can be free. An analysis of the statesponsored free CFL recycling program identified insufficient coverage at the municipal level indicating inconvenience as a key factor in reduced recycling. Based on the survey results, suggestions to increase the household CFL recycling participation rate are: (1) modify the educational effort to focus on the location of drop-off options and (2) improve convenience by expanding significantly free collection locations statewide.
\end{abstract}

Keywords: recycling, extended producer responsibility, compact fluorescent lights, convenience, municipal solid waste. 


\section{Introduction}

Compact fluorescent lights (CFLs) are an increasingly popular lighting choice and are an important component in reducing electricity consumption for residential, commercial, and institutional lighting. Based on estimated sales data, CFLs are popular worldwide. In 2007, sales of CFLs in the US reached 397 million units while sales in Europe reached an estimated 288 million units [1]. Government policies banning or restricting incandescent lights will likely boost CFL sales further. CFLs have multiple benefits including longer bulb life and reduced energy consumption, which in turn reduces $\mathrm{CO}_{2}$ and mercury emissions (if coal is used to produce electricity), wastes from electricity generation (e.g., coal, nuclear, and biomass), and air pollution control waste. However, CFLs contain a small amount of mercury that can become an environmental problem if not recycled in an environmentally sound manner. Although spotty data exists as to the US national or state CFL recycling rates for households, indications are that the vast majority of CFLs are disposed of rather than recycled. Given the increased usage of mercury-containing CFLs, the rate of recycling must be increased to recover the mercury.

\subsection{CFL usage in Maine}

The US state of Maine, the country's most northeastern state, has one of the highest residential usage rates of CFLs in the US [2]. Approximately $67 \%$ of Maine households, about 347,200, have at least one CFL installed; the average Maine home that uses CFLs has 7.2 in use [3]. Instrumental in the state's high usage rate is Efficiency Maine, a state-run program with a mission to promote the efficient use of electricity. A centerpiece of Efficiency Maine's effort is a concerted, statewide marketing and point-of-sale incentives promotion using instant rebates (US\$1.00 per lamp in-store coupon) designed to substantially increase CFL purchases and use by Maine households and businesses. Approximately 30,000 to 40,000 CFLs are sold each month through the in-store coupon program [4]. In addition, CFLs are sold in Maine without the Efficiency Maine coupon as many stores do not participate, although sales data is not available. In 2008, Efficiency Maine announced the sale of its one millionth CFL through its coupon program - more than the total sales of CFLs for 2004 through 2007 - and mailed an additional 97,000 CFLs to lower income residents [3].

\subsection{Mercury and CFLs}

There are many positive benefits to CFL use; however, a negative aspect is that sealed within CFLs is a very small amount of mercury. Newer CFLs contain an average of 1.5 to 3.5 milligrams (mg) and pre-2007 CFLs contain an average of $5 \mathrm{mg}$ [5]. The reduction of mercury as an environmental contaminant has been a legislative priority in Maine. A major step was the adoption of a state law that bans the disposal of household generated mercury-added products beginning in 2005, which includes CFLs. In support of the mercury disposal ban, the state began promoting household CFL recycling. In June 2007, Efficiency Maine 
established the first statewide household CFL recycling program in the US [5]. Household residents can drop-off intact CFLs for free at 204 participating retail stores statewide where the CFLs are collected and mailed to a regional CFL recycler [4]. In addition, there are 135 transfer facilities that collectively serve the state's 492 municipalities that collect mercury-containing lamps for recycling. Transfer facilities generally charge residents a fee of US\$1.00 per CFL [4].

CFLs that are not recycled, and instead disposed of as municipal solid waste (MSW), are subject to breakage during handling, storage, transportation, processing, and disposal thereby releasing some of the mercury into the environment (e.g., intact CFLs can break in household trash containers, through compaction in dumpsters and packer trucks, and breakage through further handling at a transfer station and/or disposal facility). Of the CFLs that survive intact and arrive at Maine disposal facilities, about $49 \%$ will be incinerated and the remaining 51\% will be landfilled. Both landfilling and incineration are likely to cause a release of mercury through volatilization from breakage and further compaction. At Maine's four waste-to-energy facilities, handling $49 \%$ of Maine's MSW, costly mercury air-pollution capture technology is required, which captures about $90 \%$ to $95 \%$ of mercury emissions. In landfills there are no mercury controls.

\subsection{Recycling of CFLs}

Because it is illegal for households to dispose of CFLs, legitimate recycling is the only legal means of disposition. A statewide residential CFL recycling rate is unknown for Maine, and is difficult to obtain because sales data is incomplete, there is a substantial time gap between date of purchase and a CFL's end-of-life (4 to 7 years), and only some recycling data is collected. (Data collected at municipal transfer stations do not distinguish between residential and commercial/institutional mercury-containing lamps.) However indications suggest that the majority of CFLs are not being recycled. For example, Maine's free CFL recycling program has had limited success: between May 2007 and September 2009 inclusive, only 10,274 CFLs were collected for recycling - a mean of 354.3 CFLs per month - a stark contrast to the 30,000 to 40,000 sold per month through the Efficiency Maine in-store coupon program [6]. There are other drop-off options. In June 2008, the national home improvement chain, The Home Depot, started its National CFL Bulb Recycling Initiative. Between October 2008 and October 2009, the 11 Home Depot stores in Maine collected and recycled $412.7 \mathrm{~kg}$ of CFL bulbs, approximately 4,100 CFLs or about 340 per month although some of the CFLs are likely to be from commercial sources [7].

In other US states, for similar reasons, accurate rates for household CFL recycling are not readily available. In 2004, the Association of Lighting and Mercury Recyclers [8] estimated the national, household mercury-containing lamp recycling rate to be only $2 \%$, a figure used by the U.S. Environmental Protection Agency (the sponsoring organization for the $2 \%$ figure stresses that the rate is not based on a scientific study). A 2004-2005 pilot study in Lane County, Oregon estimated the household recycling rate to be about $6.7 \%$ [9]. 


\subsection{Environmental impacts of low recycling rates}

According to a 2008 study by Eckleman et al. [10], when the CFL recycling rate in Maine is less than $21 \%$ there is likely a net increase in atmospheric mercury, which is based on certain assumptions regarding breakage and release of mercury in addition to reliance on coal for power generation. Thus, if Maine recycled less than $21 \%$ of CFLs, there will marginally more environmental harm, strictly from an area atmospheric mercury perspective. This, however, is not a condemnation of CFLs, per se, but recognition of the negative environmental impacts from mercury releases when there is too low a recycling rate. Clearly there are other environmental benefits of CFL use including reduced greenhouse gas emissions and avoided impacts from not having to construct additional electricity generation capacity.

\subsection{State efforts to increase CFL recycling}

To increase CFL recycling, in June 2009, Maine enacted a new state law: LD 973 - An Act to Provide for the Safe Collection and Recycling of Mercurycontaining Lighting. The law mandates a producer-financed CFL collection and recycling program. This is the first law in the US to mandate extended producer responsibility for the economic cost of recycling non-commercial CFLs. Prior to the passage of the 2009 law, in addition to the previously discussed free CFL collection system, the state has been engaged in a concerted effort to educate the public about CFL recycling in Maine. Over 40,000 copies of a brochure on mercury and mercury added products were distributed to towns for public distribution. Media print ads have run that include the phrase "CFL lamps contain trace amounts of mercury and must be recycled at the end of their life;" the printing of this same phrase is on the back of Efficiency Maine in-store coupons for CFL purchases. Efficiency Maine's CFL television advertising campaign includes a message at the end on the need to recycle CFLs [4]. However, all these messages have focused on the need to recycle and have not addressed how or where homeowners can recycle CFLs.

\subsection{Study problem}

Despite a general awareness in Maine of the negative environmental and public health impacts of mercury, the ban on disposing of CFLs, a statewide free recycling program, a statewide education outreach on the need to recycle CFLs, and the increasing use of CFLs, available evidence suggests that the household CFL recycling participation rate is very low. Because of the low rate and the prevalence and increasing use of CFLs, it is estimated that there is or will be a net increase of atmospheric mercury in Maine. In an attempt to identify factors that explain why the Maine household recycling participation rate is so low, a study was conducted. 


\section{Study methods}

To answer the research question, a survey of Maine residents who use CFLs was conducted. To maximize the reach of the sample geographically, an online survey was used. As noted by Van Selm and Jankowski [11], researchers have found online surveys to be valid and provide other benefits over traditional survey techniques as online surveys reduce interviewer bias, allow for anonymity, minimize data entry errors, provide increase convenience for respondents, and have yielded response rates on par with telephone and mail surveys.

The online survey was conducted between March 28 and May 1, 2009. The targeted population was Maine residents, 18 years or older who have at least one CFL in use in their home. Because this was an online survey, the sampling frame established the additional constraints of access to a computer, Internet access, and basic computer skills. Sampling was non-randomized haphazard and snowball. Recruitment was cross-sectional through the distribution of materials all containing the same language. Cross sectional participation recruitment was done only during the survey period through the following channels: fliers were distributed, posted, and/or mailed statewide at various commercial parking lots, transportation rest areas, retail stores, recreation areas, municipal libraries, municipal town offices, and distributed by hand in urban centers; an announcement was posted on the Maine Department of Environmental Protection (DEP) website from March 20 to April 20; notices were posted on a Face Book group and advertisements were posted through Face Book; announcements were aired by local Public Access Television stations and posted on Craig's List, press releases were mailed to various print and radio media statewide; and notices were distributed through multiple email lists. Participation was self-selected. No incentives were offered for participation or completion.

The survey instrument was created and managed through Survey Monkey. Because the URL for the survey was excessively long, a dedicated neutral website was created to serve as a portal to the survey (www.mainescflsurvey.net). There were 26 multiple choice, ranking, and fill-inthe-blank questions. The order of response options to each question was randomized, except for questions related to scale ranking, to reduce order bias. Responses were anonymous and personal information was not requested.

\section{Study results}

There were 520 respondents who satisfied the population criteria (must be a Maine resident defined as a Maine zip code, 18 years or older, reside in a housing unit other than a university dormitory or motel room, and who had at least one CFL in use). While some of the sample demographics approximate state demographics, there are a few notable differences that highlight a response bias. First, the sampling was skewed slightly toward middle-age individuals and failed to capture a sufficient number of younger (18-25) individuals. Based on reported political party affiliation, the sample did not capture enough registered 
Republicans and correspondingly too many registered Democrats. Finally, regarding education, the sample was heavily skewed toward college and graduate education. However, the age and education demographics reflect national household Internet access trends, which was this study's sampling frame. According to the U.S. Census Bureau [12], individuals with less formal education and persons over 55 years are less likely to have Internet access. Generally, studies have found age, political ideology, and education correlated to increased recycling [13-15]. Consequently, given the subject matter and demographics, the study results should be viewed as an upper-bound estimate of recycling knowledge and actions. Recognizing the limitations, the study provides valuable insight regarding household CFL recycling behavior in Maine. The following are highlights from the survey results and focuses on the following: prevalence and use of CFLs, disposition of spent CFLs, knowledge of Maine's CFL recycling program, challenges to $\mathrm{CFL}$ recycling, availability of recycling options, and prompting recycling.

\subsection{Prevalence and use of CFLs}

For households using CFLs, $48.3 \%$ of the respondents have 10 or more CFLs currently in use. The primary (73.4\%) purchase locations for CFLs are large home improvement stores, warehouse stores, and mass merchant stores (e.g., Wal-Mart). Only $17.1 \%$ of respondents indicated that a local hardware store is their primary source for CFLs, which is consistent with other studies in the US [2]. Regarding the decision to purchase CFLs, respondents indicated that conserving energy $(59.6 \%)$ was the primary factor followed by long-term cost savings (30.1\%) and global warming (5.0\%). Only 1.9\% selected the Efficiency Maine coupon as the primary reason for CFL purchase. Regarding the installation or purchase of additional CFLs, $44.7 \%$ stated that they were not discouraged, price was selected as a discouragement by $21.8 \%$, difficulty of disposal by $19.6 \%$, toxic ingredients by $17.1 \%$, poor light quality or performance by $11.5 \%$, and the disposal cost was a discouragement by $5.8 \%$ (multiple options could be selected for this question).

\subsection{Disposition of spent CFLs}

Pertaining to the disposition of intact, non-working CFLs, $23.5 \%$ of households said they either brought CFLs to a store or to a municipal facility for recycling. In contrast, $28.9 \%$ admitted that they disposed of CFLs; of these respondents $22.1 \%$ threw them into the trash and $6.8 \%$ brought them to a municipal facility for disposal. Of the remaining $47.6 \%$, respondents either did not yet have a spent CFL (23.8\%), non-working CFLs currently are in storage $(7.6 \%)$, or they did not know what they did $(16.2 \%)$. Because CFL recycling requires a special trip to a select location and would be more memorable, it is likely that many of the $16.2 \%$ who did not know what they did placed them in storage or disposed of them.

The survey results indicate that many as $23.5 \%$ of households have recycled CFLs, but this is not the same as recycling $23.5 \%$ of CFLs. The CFL collection data indicates a CFL recycling rate far lower than the household recycling 
participation rate. Moreover, the statewide household recycling rate is likely to be on overestimation for two primary reasons. First, studies on recycling have found that self-reported and actual behavior can be different and thus lead to over-estimation of recycling due to social desirability bias [16, 17]. That is, the tendency of survey respondents to over-report the performance or prevalence of socially desirable behavior (i.e., recycling) and/or under-report socially undesirable behavior (i.e., disposal). Second, as described earlier, the respondent demographics are skewed toward the population more likely to recycle and such, most likely represents an upper-bound estimate of recycling rather than the mean due to non-response bias. If the sample were truly representative of the state population demographically speaking, the recycling rate would be lower. Interestingly, despite the low recycling rate, respondents expressed a high degree of recognition that CFLs contain mercury. In response to the question, "Which of the following toxic components are commonly found in CFLs," $76.8 \%$ of the 469 respondents correctly identified mercury.

\subsection{Knowledge of Maine's CFL recycling program}

In spite of the state's requirement to recycle CFLs, $72.9 \%$ stated they did not know if CFLs are required to be recycled or responded incorrectly that there is no such requirement. Of the respondents who stated that they knew about the recycling requirement, $17.2 \%$ of them said they disposed of CFLs as trash. Therefore some respondents chose not to recycle in spite of contrary knowledge, indicating that other factors are influential (e.g., convenience).

\subsection{Challenges to CFL recycling}

Respondents were asked to select all the challenges experienced in recycling CFLs. The most prevalent response $(42.9 \%)$ was no challenges followed by not recycled any CFLs yet (31.4\%), and then lack of time $(9.8 \%)$. While respondents who recycled may not have faced any challenges, it is unclear as to whether respondents selected this response because they did not face challenges, had not recycled, or had not yet had a spent CFL. Otherwise, the responses were within the expected range for recycling programs, such as inconvenience (i.e., includes convenience, lack of time, and location), lack of awareness, or cost.

\subsection{Availability of recycling locations}

When asked whether the respondent knew the specific location where CFLs can be recycled, $64.2 \%$ said no and $35.8 \%$ said yes, which is higher than the reported household recycling participation rate. Respondents who answered yes were requested to specify the location. Of the respondents who said yes, $66 \%$ provided locations.

As discussed earlier, there are 204 stores participating in the state's free CFL recycling program (Efficiency Maine partner stores). As shown in Table 1, local hardware stores are the most predominant (44\%) and less than $1 \%$ of the stores are large home improvement stores, which does not match the primary purchase 
locations of CFLs by Maine residents. In addition to these 204 stores partnering with the state, other stores voluntarily have initiated free CFL drop-off opportunities (e.g., The Home Depot) or sponsor periodic drop-off events. Regarding the location of the Efficiency Maine partner stores, there is significant disparity between the number and location of participating stores and the state's population centers. Only 113 of the 492 state's municipalities (22.9\%) are served by a participating store. The 10 cites with the highest populations, representing $20.4 \%$ of the state's population, collectively have only $24(11.7 \%)$ of the participating stores. These data suggest that an additional challenge to recycling is convenience: the availability of free drop-off locations within a convenient driving distance as there is no curbside pick-up of CFLs for recycling in Maine.

\subsection{Prompting recycling}

When asked which factors would most prompt the respondent to recycle CFLs, environmental responsibility was the most prominent (38.4\%). The other factors can be grouped into economic incentives and convenience. Economic incentives were cited by $30.4 \%$ of the respondents (Free Recycling $=21.9 \%$ and Recycling Rebates/Coupons $=4.5 \%)$ and $28.1 \%$ selected convenience $($ Convenience $=$ $22.2 \%$ and Proximity to Drop-off $=5.9 \%$ ).

\section{Discussion}

CFLs are in wide use and sales are increasing primarily due to energy savings and state subsidies. It is reasonable to assume that as energy prices increase, if the retail price of CFLs continues to remain stable or decrease, and restrictions are posed on incandescent lights, CFL usage will increase. This means that the collective amount of mercury in household CFLs will be increasing. Assuming that the recycling rate in Maine remains below $21 \%$, which is likely the current situation, there will be a net increase in atmospheric mercury from the disposal of CFLs. As a result, the CFL recycling rate must be increased to reduce atmospheric mercury emissions in Maine.

Table 1: Efficiency of Maine partner stores by type compared to primary purchase locations of CFLs by Maine households.

\begin{tabular}{|c|c|c|c|}
\hline Store Type & Number & Percent & $\begin{array}{c}\text { Where CFLs } \\
\text { Purchased }\end{array}$ \\
\hline Hardware Stores & 90 & $44.0 \%$ & $17.1 \%$ \\
\hline Grocery Stores & 34 & $16.6 \%$ & $8.3 \%$ \\
\hline Building Supply & 31 & $15.0 \%$ & \multirow{2}{*}{$6.3 \%$} \\
\hline Miscellaneous & 18 & $8.8 \%$ & \\
\hline Department Stores & 17 & $8.3 \%$ & $4.0 \%$ \\
\hline Mass Merchant & 11 & $5.4 \%$ & $20.0 \%$ \\
\hline Home Improvement & 3 & $<1.0 \%$ & $44.7 \%$ \\
\hline
\end{tabular}


The results from this particular survey indicate that the household recycling participation rate is near $24 \%$, which as discussed earlier, likely overestimates the statewide participation rate. It is important to note that this rate merely measures participation of households in recycling rather than the percent of CFLs actually recycled, which based on the evidence, is substantially lower. This study sought to identify the factors that are likely causes of low recycling participation in households in spite of state law, education efforts, and free recycling locations. Based on the survey, insufficient knowledge and inconvenience appear to be the most influential.

The survey results suggest that lack of knowledge is a highly influential factor in the low recycling rate, which agrees with other studies $[18,19]$. The state's multi-media education and outreach efforts have focused on purchasing and installing CFLs; the need to recycle CFLs has been a secondary message. Most of the survey respondents (in spite of comparatively high level of education) were unaware of the state CFL recycling requirement. Similarly, there was a high degree of unawareness as to where CFLs can be recycled and most respondents also were unaware of the free, state-sponsored recycling option. Yet, the majority of respondents knew CFLs contain mercury.

Similar to many studies assessing recycling participation, the survey findings also identify convenience as an important factor in recycling participation [19-22]. While Maine's program has attempted to promote recycling through statewide education and by offering a free recycling drop-off program, household recycling of CFLs remains inconvenient for the general public because individuals must drive to a designated drop-off location, there are too few free drop-off locations, and most municipal drop-off locations charge a recycling fee. Moreover, CFLs are a low value recyclable and generated at an unpredictable, low rate. The free statewide CFL drop-off system relies heavily on local hardware stores, but the majority of respondents do not purchase CFLs at local hardware stores nor do they likely shop at such stores on a routine basis. And, as discussed previously, the coverage of the current free CFL collection system is inadequate. Most of the state's population is not located within a convenient distance of a free collection location. Only $23 \%$ of Maine's municipalities have a participating store and the state's most populous cities are comparatively underserved. Moreover, because many of the state's population centers also have curbside collection of recyclables, individuals are not used to having to drive to drop-off recyclables; making a special trip to drop-off a CFL (which may charge a fee) would be inconvenient. Consequently, based on this study, two specific areas need to be addressed to increase the household recycling rate of CFLs; modifying the education program and increasing the convenience of collection.

\subsection{Modifying the education program}

The current education efforts have focused on purchasing and using CFLs. These efforts have mentioned the need to recycle only briefly, but details on how and where are not provided. Implicitly, the impetus has placed been upon households to seek out this information. The education efforts need to be modified to 
reorient the message away from the need to recycle to focus on educating the public specifically on the locations for free CFL recycling. By focusing on the locations of free CFL recycling as the primary message, the secondary message conveyed is that CFLs need to be recycled. While additional research should be conducted on effective messaging and social marketing techniques to deliver the primary message, the following important steps should be taken:

1. Create a dedicated, simplified website specifically for CFL recycling information to include a user-friendly map and list of drop-off locations. Drop-off locations should be kept current and should include contact information and days and times of operation. The website should use a simple, short, and memorable Uniform Resource Locator (URL).

2. Label each CFL package with a vibrant sticker that includes the phrases "Must be Recycled" and "Maine CFL Recycling Information www.xxx.xxx" and include the CFL recycling URL.

3. Post and continuously distribute the CFL URL at all municipal transfer stations, town and city halls, though utility bills, and on a tear-off section (which could be retained by the purchaser) of the Efficiency Maine CFL instore coupons.

4. Using the print media, periodically list specific locations of participating stores that will accept CFLs for free.

\subsection{Increasing convenience of collection}

The greater focus must be on reducing real or perceived inconvenience to dropping off CFLs by increasing significantly the number of free collection locations generally deemed convenient by households. For example, because most (73\%) respondents purchase CFLs from home improvement, warehouse, or mass merchant stores, these point-of-sale locations should also be required or encouraged to have free CFL collection facilities (in addition to local hardware and large chain grocery stores). Also, free collection containers should be made available at MSW transfer stations and municipal offices. Because CFL recycling mail-in kits are available, CFL point-of sale locations could offer these kits directly for free, through a mail-in coupon, or through an online request using the state CFL recycling website. Given that special packaging exists for individual CFL recycling, periodic curbside recycling deserves consideration and study as it would significantly reduce inconvenience.

\section{Conclusion}

Until newer lighting technology becomes mercury-free, cost effective, and readily available, the use of CFLs by households will likely increase. Regardless of state laws and programs to encourage otherwise, this study highlighted two primary factors that minimize the household CFL recycling rate; insufficient knowledge and convenience for household drop-off of CFLs. Countries, states, provinces, and municipalities should consider these two factors, which based on this survey, are more influential than disposal bans. Through targeted education, 
households need to know that CFLs should and can be recycled, they need to know where and how they can be recycled and, of paramount importance, the drop-off of spent CFLs needs to be made as convenient as possible.

\section{References}

[1] McKeown, A. \& Swire, N. Strong Growth in compact fluorescent bulbs reduces electricity demand. World Watch, 22(1), p. 29, 2009.

[2] Unites States Department of Energy. Big results, bigger potential. CFL market profile, March 2009, Online. www.energystar.gov/ia/products/ downloads/CFL_Market_Profile.pdf, 2009.

[3] Maine Public Utilities Commission. Efficiency Maine, 2008 Annual Report, Online. www.efficiencymaine.com/pdf/EMO14758_EMAnn.Rept_v11.pdf.

[4] Maine Department of Environmental Protection. Report Regarding the Recycling of Fluorescent Lamps and Consumer Education Efforts, Online. www.maine.gov/dep/rwm/homeowner/fluorescent.htm, 2008.

[5] Barnes, P. \& Bacon, R. Maine's model recycling program. In Proceedings of the 2008 ACEEE Summer Study on Energy Efficiency in Buildings, pp. 215 to 2-26. Washington, DC.: American Council for an Energy-Efficient Economy. 2008.

[6] Maine Public Utilities Commission. Efficiency Maine, 2009 Annual Report, Online.

www.efficiencymaine.com/pdf/EM_AnnualReport2009_FINAL.pdf.

[7] Wroblewski, T. Personal communication, 5 October 2009, Manager of Regulatory Compliance \& Environmental Programs, The Home Depot, Atlanta, GA, USA.

[8] Association of Lighting and Mercury Recyclers (ALMR), National Mercury-Lamp Recycling Rate and Availability of Lamp Recycling Services in the U.S., Online. www.lamprecycle.org/public/images/docs/ALMR capacity_statement.2004.\%20pdf.pdf, 2004.

[9] Northeast Waste Management Officials' Association, Review of Compact Fluorescent Lamp Recycling Initiatives in the U.S. \& Internationally, Online. www.newmoa.org/prevention/mercury/lamprecycle/ CFLRecyclingReport. pdf, 2009.

[10] Eckleman, M.J., Anastas, P.J., \& Zimmerman, J.B., Spatial assessment of net mercury emissions from the use of fluorescent bulbs. Environmental Science \& Technology, 42, pp. 8564-8570, 2008.

[11] Van Selm, M., \& Jankowski, N.W., Conducting online surveys. Quality \& Quantity, 40, pp. 435-456, 2006.

[12] U.S. Census Bureau, Computer and Internet Use in the United States: October 2007, Table 1, Online. http://www.census.gov/population/www/ socdemo/computer/2007.html, 2007.

[13] Nixon, H. \& Saphores, J.D., Financing electronic waste recycling: Californian households' willingness to pay advanced recycling fees. Journal of Environmental Management, 84, pp. 547-559, 2007. 
[14] Kipperberg, G., A comparison of household recycling behaviors in Norway and the United States. Environmental \& Resource Economics, 36, pp. 215$235,2007$.

[15] Tucker, P. \& Speirs, D., Attitudes and behavioural change in household waste management behaviours. Journal of Environmental Planning and Management, 46, pp. 289-307, 2003.

[16] Corral-Verdugo, V., Dual realities of conservation behavior: self-reports vs. observations of re-use and recycling, Behavior Journal of Environmental Psychology, 17, pp. 135-145, 1997.

[17] Barker, K., Fong, L., Grossman, S., Quin, C., \& Reid, R., Comparison of self-reported recycling attitudes and behaviors with actual behavior. Psychological Reports, 75 (1), pp. 571-577, 1994.

[18] Lansana, F.M., Distinguishing potential recyclers from nonrecyclers: a basis for developing recycling strategies. Journal of Environmental Education, 23(2), pp. 16-23, 1992.

[19] Vining, J. \& Ebreo, A., What makes a recycler? A comparison of recyclers and nonrecyclers. Environment and Behavior, 22(1), pp. 55-73, 1990.

[20] Saphores, J.M., Nixon, H., Ogunseitan, O.A. \& Shapiro, A.A., Household willingness to recycler electronic waste: an application to California. Environment and Behavior, 38(2), pp. 183-208, 2006.

[21] Peretz, J.H., Tonn, B.E. \& Folz, D.H., Explaining the performance of mature municipal solid waste recycling programs. Journal of Environmental Planning and Management, 48(5), pp. 627-650, 2005.

[22] Ando, A.W. \& Gosselin, A.Y., Recycling in multifamily dwellings: does convenience matter? Economic Inquiry, 43(2), pp. 426-438, 2005. 